DOI: $10.52950 /$ TE.2021.9.2.005

\title{
UNVEILING THE HIDDEN BEAUTY OF THE SOUL: A QUALITATIVE JOURNEY INTO POETRY THERAPY
}

\section{JUNE TYSON}

\begin{abstract}
:
Poetry is writing is good for the soul. Everything in life is poetry if we learn to look at it from various perspectives. However, it is very difficult to see poetry in the life of a recovering addict. Their experiences, hurts, deep pain, offenses, crimes, hunger and low self-esteem is all this population can focus on. They are trying to repair their lives and are often confronted with these elements of their past. This study takes recovering addict and provide them with a safe space to do creative writing about their experiences. This creative form is poetry. Many of the participants never wrote poetry before but by digging deep within themselves, they were able to find the words to fit their feelings and experiences. They were surprised to see what came into fruition.
\end{abstract}

\section{Keywords:}

Poetry, Safe space, Writing, Recovery

JEL Classification: D80, D83, D80

\section{Authors:}

JUNE TYSON, Home, United States, Email: junetyson@gmail.com

\section{Citation:}

JUNE TYSON (2021). Unveiling the Hidden Beauty of the Soul: A Qualitative Journey into Poetry Therapy. International Journal of Teaching and Education, Vol. IX(2), pp. 58-68.,

10.52950/TE.2021.9.2.005 
Poetry is when an emotion has found its thought and the thought has found words.

$\sim$ Robert Frost

The above quote express a major benefit of poetry. Poetry gives voice to ones feelings, thoughts, insecurities, pain and many other human emotions. In doing this, poetry unveils the hidden beauty of the soul. It shows the depth and richness of experiences in a creative form. It provides comfort in a world of pain.

\section{Purpose}

This research project examined a group of participants' involvement together in Poetry Group Therapy. The purpose of this study was to explore how poetry therapy assists in motivating participants to share their feelings in literary form and therefore cope with their life's struggles in a group setting. It sought to understand how this form of therapy affects the dynamics of a group as they share their poetry with each other.

\section{Significance}

With the information gathered from this study, human service workers can use poetry therapy to assist their patients and clients in expressing and coming to terms with their feelings. The participants all have a history of mental illness and substance abuse. Therefore, this study will add to established research on poetry therapy as it pertains to participants who are mentally ill and chemically addicted, (MICA) patients.

\section{Positive Psychology}

A pessimist sees the difficulty in every opportunity; an optimist sees the opportunity in every difficulty."

\section{Winston Churchill}

The researchers desired to use poetry therapy as a positive way to treat their patients. The above quote shows the heart of this endeavor as creative writing brings out positive emotions. Carson (2012) states, that creative activity (such as poetry writing) can reduce anxiety and stress. It even has the power to aid in the healing process if trauma or injury has experienced.

In 1962, Joy Shieman, poet and mental health professional began using poetry therapy with her patients in a hospital in California. Authentically and naturally, this right hemisphere of the brain approach to healing action of poetry therapy attended to what she has always viewed as a lack within the psychiatric picture - "a realignment of the soul." Because of her research, many others in the helping professions began using poetry therapy with great success with many different populations.

Our explored how Poetry Therapy with Positive Psychology as the theoretical framework. What is positive psychology? Positive Psychology is a new branch of psychology, which focuses on helping people live happier lives. It is the scientific study of the strengths and virtues that enable individuals and communities to thrive. The field is founded on the belief that people want to lead meaningful and fulfilling lives, to cultivate what is best within themselves, and to enhance their experiences of love, work, and play.

The key figure in this movement is Dr. Martin Seligman, Director of the University of Pennsylvania Positive Psychology Centre. 
Psychology has tended in the past to focus on dealing with problems. Positive Psychology does not ignore the weaknesses of a person; instead, it focuses on building the strengths of a person.

Seligman's (2016) research has led to the definition of 24 "character strengths" grouped under 6 "virtues." The identified virtues are wisdom and knowledge, courage, humanity, justice, temperance and transcendence. The researchers of this study examined how poetry therapy brings out the six virtues of Positive Psychology. These virtues identified qualities in the participants together with examples of associated character strengths.

\section{Wisdom and Knowledge}

Schwartz and Sharpe (2016) suggest that wisdom is in many respects the master virtue and without wisdom, other virtues or character strengths fail to produce effective action.

We looked for ways poetry therapy brought out wisdom and knowledge from the patients. For example, did the poetry the patients produced show that they were open-minded? Did they have a love for learning? Were they creative?

\section{Courage}

Courage is related to the concepts of self-esteem, free will, and personal values in life (Wein, 2016). We asked the following questions about the participants regarding courage. Did the patients' poems manifest their zest? Did they display persistence? Were they free enough to be authentic?

\section{Humanity}

Most research has focused on the failure to ascribe humanity to others (Haslam, Loughnan, Reynolds, \& Wilson, 2017). We focused on how humanity may influence how the participants created and expressed their poetry.

We looked for kindness and love from the patients' poems. We sought to discover if they would show kindness towards other members in the group. In addition, the researchers looked for ways they showed humanity in their everyday lives as they discussed the meaning of their poems.

\section{Justice}

Colquitt \& Shaw (2015) state, perceptions of justice or fairness have consistently been shown to relate to important work attitudes and behaviors such as organizational commitment, citizenship behavior, performance, turnover intentions, and satisfaction. However, it is important for us to know if signs of fairness to themselves and individuals and to others were exhibited in the patients' poetry. We looked for evidence of leadership among each other in the group. In addition the looked for ways teamwork would be displayed.

\section{Temperance}

We expected there to be a certain amount of anger and despair in the poetry of the participants due to their mental health diagnosis and substance abuse histories. Therefore, we listened for words of forgiveness in the poetry or in the discussions. We looked for any ways the participants may or may not have shown modesty in the sessions.

\section{Transcendence}

Transcendence has been significantly related to measures of quality of life and life meaning and correlated with depression and overall mental health (Ellermann \& Reed, 2013). We desired to know whether the participants were able to move above any negative circumstances. It was expected that the participants would manifest this in their poems and in their discussions. Signs 
of gratitude, humor, hope, appreciation of beauty and excellence and religiousness would have shown if they did or did not.

In conclusion, the theory of Positive Psychology was used to examine the participants' involvement together in poetry group therapy. This theoretical framework was used to explore how poetry group therapy assists in motivating participants to share their feelings in literary form and therefore cope with their life's struggles in a group setting. Finally, Positive Psychology was used to understand how this form of therapy affects the dynamics of a group as they share their poems with each other. The next section of this study will discuss the methodology used to conduct the research for this dissertation.

\section{Methodology}

Do not go abroad. Truth dwells inside man.

-Augustine

Augustine's quotation describes the heart of phenomenological, qualitative research. This is the methodology we used to conduct this study. We choose this methodology because it has the ability to bring about rich and detailed information. The phenomenological approach potentially enriches our experience by bringing out aspects of an experience that may otherwise be neglected (Sternberg, 1985).

\section{Research Design}

We used the phenomenological approach by asking the participants in depth questions that required a great deal of thought and insight into their histories. The questions were open-ended. It provided the opportunity for the participants to explore their feelings about their poems and their way of life.

\section{Participants}

There were five participants, four males and one female. Four participants enjoyed a history of poetry writing. One had never written poems until his time with us in the group. They all were active members of the group for 1 year.

All the participants have a history of substance abuse and depression. There ages range from 25 to 50 years old.

\section{Data Collection}

As stated previously, the participants were asked a list of open-ended questions regarding their experience in poetry group therapy. Copious notes were taken. We used pseudonyms for each participant to protect their identities. Tesch (1990) indicates that this form of interviewing motivates the participants to share their experiences and permits the researcher to understand their experience in greater depth. Each interview lasted approximately 30 minutes in a conference room of a mental health center. After the data was collected, we reviewed the notes and analyzed them for themes.

\section{Ethical Considerations}

This researchers' position regarding poetry group therapy is one of openness and inquisitiveness. This tool can assist people of all backgrounds. We have no relationship with the problem in a way that affected the fashion in which the data was presented. Therefore, no conflict of interest interfered with the researcher's presentation of the findings of the data. We are interested in the 
topic because of our professional curiosity in poetry group therapy and Positive Psychology. We desired assist the Human Services field by sharing how poetry group therapy can assist in the personal growth and development of patients with histories of substance abuse and mental health diagnosis.

The next section will show the information collected from the participants. It will describe the main points of what they shared during the interviews. Finally, it will answer the questions we have regarding the participants' growth as a result of poetry group therapy.

\section{Data Analysis}

Poetry is nearer to vital truth than history.

-Plato

During the time the group met, the researchers paid close attention to the variety of poems presented by the participants. From the poems, the researchers were able to gain a better understanding of the essences of their experiences. After a year of meeting in poetry group therapy, researchers met with the participants to obtain answers to the research questions below. Research Questions

The primary questions we wished to explore were the following:

1. Does one develop and grow as an individual, because of poetry group therapy?

2. Are the elements of poetry group therapy used in everyday life (stress, joy, anger, sadness etc.)?

3. Does poetry group therapy assist in dealing with major losses in life?

4. Are group dynamics affected because of sharing poetry?

5. Does poetry group therapy assist the participants with coming to accept and make peace

with their history of substance abuse?

Below is a sample of the answers received from the participants. No identifying information is contained in these narratives. Pseudonyms were given to each participant to protect their identity.

Randy

1. Yes it has definitely. When I first came to poetry therapy, I didn't know what to do. Then I started to put my feelings down on paper. At first I only knew how to write about my anger. Now I can sit down, I put my music on and I go deep Inside. I write about how I truly feel. I write about my daughter, and my life. Poetry therapy has changed me. My writing has changed. Before I used to write about factual things; like my life in prison, robbing people, and doing time. I used to just tear up the paper after I wrote. Now I look back on what I've written. I look back at my life and my feelings and I see how I've changed and how my outlook on life has changed.

2. Yes when I feel joy, I can open up and write a book. I write about whatever I'm feeling joy, confusion, sadness, anger. I write about the joy of having hope, and being 
given a second chance. I write about the sadness and anger I feel at not seeing or being In contact with my daughter. When you write in a poem you back to what you were feeling and it is very helpful. I read one of my poems in church and I felt so much more confident. Before poetry therapy I would never have thought that I could write like that, not to mention doing public reading. I would never have wanted to speak in public far less read. Because of poetry therapy I can see or feel something and write about it.

3. Definitely. Not seeing my daughter for so many years was very traumatic. I left my daughter when she was 2 years old. I finally got to see her at the age of 15 she asked me so many questions. I told her the truth. I held nothing back. After 18 months of seeing my daughter, her older sister took my daughter's phone away from her. That meant that I had no means of contacting her. The pull on my heart, the depth of loss that I felt and the anger at myself for not seeing her for so many years all those emotions over-powered me. Thanks to poetry therapy I was able to put all those feelings on paper. I wrote about how much I loved my daughter. Before, I used to just write that things were ok. Not anymore. Now I write about how much I miss my daughter. I hope to read my poems to her one day. I hope to show her what l've written. I write about my anguish of not having any contact with her. I write poems about the times that I got to hug her, see her and just be with her. Having that outlet really makes me feel better.

4. Yes because you have a group of people that come together using the same outlet to help them. It's a small group that bonds based on words. When I started, I was able to share my feelings. I felt that I was really accepted. I can pull someone in the group aside and speak about things that are important to me. I feel really connected to the people at CCM. I can release the hate, anger or any other emotion that I am feeling. I get great support from the group. I can open up.

5. Yes. I wrote poems that dealt with my past. I wrote about the darkness that I was going through. I wrote about my life on the street. I wanted to block out the abuse from my father, the drinking and drugging. I wanted to block out everything. Poetry therapy helped me put all down on paper. Poetry Therapy helped me to accept my past. When I put my feelings on paper, and speak about my drug and alcohol abuse, I can accept that these things were a part of my past. I am able to accept that no-one put a gun to my head. I am truly thankful that I can accept my past and move forward. Poetry therapy helped me to do that.

Mark

1. In my case it did. I was already into poetry, so I knew the benefits of poetry. I just didn't think that poetry could be actual therapy. With poetry therapy, I was able to let out everything and forget. I put what I feel and what's on my mind in writing. I don't like to carry baggage of any kind, especially emotional. so poetry therapy was great. I was able to let go of my past. I was able to let go of the anger, the frustration, the hurt, everything. It's great to have a place to let your feelings out. Now I really pay attention to the street poets. I watch people's reaction. When I'm sitting involved in poetry therapy I can express how I really feel. When I go to the place that I live. I can't write. My mind is blank. But with poetry therapy I find peace and tranquility. 
2. Oh yeah. It is like getting on stage and reciting your poem. You take a deep breath or you take a small breathe and then it's you. I live like I'm on stage. So my life is basically immersed in Poetry Therapy. No matter what the situation, Poetry Therapy helps me to remain in control of my stress, my anger, and my frustration. Poetry Therapy is even helpful in grammar. I learn so many new words and my vocabulary has improved.

3. Well in my case it's 50/50. For me once something is done, a relationship, a conversation it's done. Once I feel something and I no longer feel it that's it. I don't dwell on things. For instance I thought about how long it took for me for find out that my grandmother was buried. Because of Poetry Therapy, I was able to write about my feelings both toward my grandmother and about my feelings in finding out that I didn't learn about her burial until so many years after. I only write about my immediate family or people that I consider my family. Poetry Therapy also allowed me to write another poem about loss. This time it dealt with the powerful effect of my mother's words on me. Poetry Therapy allowed me to realize how much I felt about what she said.

4. Oh Yes. I feel a lot of positive energy from the participants in the group. The participants in the poetry therapy group make me want to compete. I like to hear other people's poetry. I like to hear how that person's poem relates to what I'm going through. I feed off of their energy.

5. Well since I have a history of substance abuse, I have to say yes. One of the $1^{\text {st }}$ poems I wrote, I wrote about when I was drinking very heavily. I read that poem so many times over and over again. After writing that poem I couldn't write about anything for a long time. I finally had to face the fact that I will always have to work on my addiction. Writing about my addiction reminds me that I must always work on myself. With Poetry Therapy knowing that I was able to write about my addiction, it gets easier for me to let go and realize my reality. Writing allowed me to face life when nothing else could.

Carl

1. Yes. It helped me to express myself. It was basically a soul cleanser for me. I was nervous to share my life experiences to anyone and in any form. It helped me to express the way that I was feeling. I really feel better when I write.

2. Definitely. I think about writing even on the weekends. I have poems that I have thought of then I convert them into paper. In fact I read my poetry to my girlfriend and she took two of them. I believe that poetry therapy makes me responsible. It motivates me. Poetry Therapy reminds me that I need to keep my commitments. When I don't come to poetry therapy, I feel that I let my group members down.

3. It helps me a lot. All I ever wrote about was my wife. I wrote a lot of love stories. I wrote about positive things, I wrote about hurtful things. I wrote about illnesses. I wrote 
about cancer. After writing my poems, I would often go back and re-read my poems. Poetry Therapy helped me to heal and the therapy is still helping me to heal.

4. I was a loner. Poetry Therapy helped me to open up. I was shy. But Poetry Therapy helped me to share. I was able to get everything out. Before Poetry Therapy, I used to be afraid to share my feelings. Now, I share a lot. In other groups people are not regular they drift in and out. In Poetry Therapy the attendance is consistent. In the other groups they talk about one specific thing. In Poetry therapy we talk about a lot of different things.

5. Yes. Poetry Therapy kept me disciplined. Poetry Therapy allows me to have a clear mind especially when I think about my addiction. I feel better when I write. I can really express my honest and heartfelt feelings about what I went through and about how I'm handing my addiction. It's been a year since I passed my $6^{\text {th }}$ months of being sober and I passed that year while attending poetry therapy. I was able to share that with my group members, some of whom have similar histories.

Bette

1. Yes. I have bad anger issues. I use poetry therapy as a vital coping skill. It helps me to remove myself from my current situation. In fact I have 2 books that I use to write in. I write how I feel. Poetry calms me down. I can go back to my writings, especially when I'm angry. Poetry allows me to tell me life experience on paper.

2. Yes. I carry both my poetry books with me and I also make mental notes. But, if I can't make mental notes then I write on the cover of one of my books and I often go back to those notes, especially if I'm in a setting where I can't write.

3. Yes, but you're still thinking about it. A month ago, a friend who passed away, I wrote a poem which really helped me. I was able to go to backyard of my residence and not cry. It made me really look up who he was. Poetry Therapy allowed me to connect to his family. I felt as if a big bolder was lifted off. It really helped to write.

4. I was writing poetry from the age of 13. The Poetry Group really helps. I go by people's energy. One of group members, Charles read a poem and I felt a deep connection. Charles' poem was about relationships and I was able to write about my relationships. Charles also gave me feedback. His feedback was very important and really helped me because it made me feel more comfortable in the group. I was also able to connect with Matthew, even though I don't really understand his poems. I also connected with Ralph because Ralph expresses himself so well. I also connected deeply with Jeremy who is a recent member of the group. I really liked his poems. He also gave me great advice. We connected so well that even after group was finished we would have great conversations. The friendships that I made in the Poetry Group are real. We talk on a regular basis, and without the poetry group we would not have met. 
5. Well since I was born addicted to crack, Poetry Therapy definitely helps. I never found out about my birth addiction until 2 days before my $20^{\text {th }}$ birthday. My sister told me. I never wrote about it, but I can now.

\section{Conclusion}

"Poems are never finished - just abandoned"

- Paul Valéry

In conclusion, it was determined that Poetry Therapy is a positive, effective, and necessary coping method for today's patients. Our study provided concrete evidence that irrespective of their diagnosis, history, background, or gender; patients benefited from Poetry Therapy. Patients seemed to have enhanced progression in their treatment after they participated and utilized Poetry Therapy. We observed that patients applied Poetry Therapy as a regular part of their daily routines; even using it when they were not in a therapeutic setting. Patients wrote while using public transportation, at their residences, in public facilities such as parks and libraries, and during leisure time. Patients also shared their writings with other members of the Mental Health community, their family and friends, their support systems, and individuals from the general community.

\section{The Lessons of the Six Principles of Positive Psychology}

As the participants grew and developed during the course of 1 year, the researchers also grew. The Six Principles of Positive Psychology were made very apparent. The researchers were able to see these attributes very clearly in the participants' poems and in their overall lifestyle. Wisdom and Knowledge

The diversified background of our patients brought out their immense experience with varied situations and their knowledge of many skills and trades. The patients' poems also created a cohesive atmosphere which allowed constructive feedback. Group members conversed about effective coping techniques that were invaluable. This environment also stimulated group discussions about current and future crisis and challenges; and allowed group members to write on these topics.

\section{Courage}

Group members spoke and wrote about topics that society deemed as taboo. This took a great deal of courage. Some members were shy about meeting new people and about reading their poems in front of individuals that they did not know. For other members, this was the first time that they read their poems aloud, and it gave them an additional forum to share their poetry. Most members felt fearful about writing about cutting, depression, and suicide. These were topics that were not positively received by family, friends or the general public. This took incredible courage and both the facilitator and the group members benefitted.

\section{Humanity}

As professionals in the field of Counseling and Psychotherapy we are aware that the core of our field is understanding the basic humanity of our patients. The base of our patients' humanity is their emotions. We cannot work with our patients if we do not consider or address their emotions. As our patients wrote and read their poems, it was evident that their motivation came from their feelings; and the effect that those feelings and emotions had on their life experiences. 


\section{Justice}

During our study, we found that our patients wrote on various topics. Since our patients' motivation comes from their life experiences, it was inevitable that the subject of justice would be a major point of discussion. Our patients often communicated their frustration at the lack of justice that they felt from the community at large. Patients often complained that organizations whose clientele were individuals from the Mental Health population; and whose main objection was to serve that community, were often the most unjust.

\section{Temperance}

It is important to note that most of our patients have backgrounds of substance abuse; therefore, temperance is an issue that they are consistently dealing with. This is true even with patients who are former substance abusers. Our patients' writings often reflected past and current traumas. The poems that emanated from our patients, frequently transcended into fruitful and essential discussions that dealt with beneficial coping skills, the pain of their addictions, the effect on their family and friends, and the effects on their current life.

\section{Transcendence}

Our study concluded that everyone experienced transcendence; the patients and the therapists. Some of our patients were surprised as they realized that they were able to write on subjects and styles that they were unfamiliar with and unaccustomed to. Other patients found that they wrote to higher degrees and levels. As therapists, we found ourselves in awe as we observed the scope of our patients' ability, the compassion and empathy that they showed to one another, and the depth of their commitment to their treatment.

\section{Recommendations for Further Study}

After conducting this study and observing the results, we are convinced that was immeasurably beneficial to our patients. Therefore, we like to recommend a future study be conducted with patients who have been incarcerated. We believe that Poetry Therapy would be fundamentally useful to these patients. Our study concluded that patients with substance abuse and traumas immensely benefitted. Since this study was conducted at a Mental Health facility, we would like to observe the results with individuals who have a similar background but who are not Mentally III. It would also be interesting to observe the effects on individuals who are in a controlled environment. Thus, we will be able to provide concrete evidence that Poetry Therapy is an effective coping skill for individuals irrespective of their backgrounds or illnesses.

\section{References}

Colquitt, J. A., \& Shaw, J. C. (2015). How should organizational justice be measured? In J.

Greenberg \& J. A. Colquitt (Eds.), Handbook of organizational justice (pp. 113-154).

Mahwah, NJ:Lawrence Erlbaum Associates.

Ellermann, C.R, \& Reed, P.O. (2011). Self- transcendence and depression in middle-age adults. Western. Journal of Nursing Research, 23, 698-713.

Haslam, N., Loughnan, S., Reynolds, C., \& Wilson, S. (2017). Dehumanization: Anew perspective. Social and Personality Psychology Compass. 1, 409-422

Schwartz, B Sharpe, K. (2006) Practical wisdom: Aristotle meets positive psychology. Journal of Happiness Studies. 7, 677-395. http://www.militarymentalhealth.org/blog/2012/03/creativity-can-combatnegative-emotions/ 
Seligman, M.E.P., Rashid, T., \& Parks, A.C. (2016). Positive psychotherapy. American Psychologist, $61,774-788$.

Sternberg, R.J. (1985). Beyond IQ: A triarchic theory of human intelligence. Cambridge: Cambridge University Press.

Wein, S. (2017). Is courage the counterpoint of demoralization? Journal of Palliative Care. 23, 40 pg. 3. 